\title{
Complex Formation of Platelet Thrombospondin with
}

\section{Fibrinogen}

\author{
Lawrence L. K. Leung and Ralph L. Nachman, Department of Medicine, \\ Division of Hematology-Oncology, The New York Hospital- \\ Cornell Medical Center, New York 10021
}

\begin{abstract}
A B S T R A C T Using an enzyme-linked immunosorbent assay, we have demonstrated that purified human fibrinogen forms a complex with adsorbed platelet thrombospondin. The formation of the fibrinogenthrombospondin complex was specific, saturable, and partially inhibited by mannosamine, glucosamine, and arginine. These same inhibitors have been previously shown to block thrombin-induced platelet lectin activity and platelet thrombospondin lectin activity. Adsorbed thrombospondin also formed a complex with fibronectin, although the extent of complex formation was significantly less than the extent of formation of the fibrinogen-thrombospondin complex. Platelet membrane glycoproteins IIb and IIIa, which have been previously shown to bind fibrinogen, did not inhibit the formation of the fibrinogen-thrombospondin complex. The present study supports the hypothesis that the interaction of fibrinogen with thrombospondin on the activated platelet surface may be an important step in the platelet aggregation process.
\end{abstract}

\section{INTRODUCTION}

Certain primitive cell systems, such as cellular slime molds, exist either in a unicellular vegetative form or a differentiated form in which they become adhesive and aggregate into a multicellular structure. When the cells become adhesive, they synthesize surface polyvalent carbohydrate-binding proteins or lectins that mediate cell-to-cell adhesion (1). Cell adhesion in the slime mold takes place via interaction of carbohydrate

A preliminary report of this study was presented at the Annual Meeting of the American Society of Hematology, San Antonio, TX, 7 December 1981, and published in abstract form in 1982. Blood. 58(Suppl. 1): 199a.

Dr. Leung is the recipient of Clinical Investigator Award K08 HL00877-01 from the National Heart, Lung, and Blood Institute. Address reprint requests to Dr. Leung.

Received for publication 28 December 1981 and in revised form 30 April 1982. binding sites of the cell surface lectin with high affinity membrane glycoprotein $(\mathrm{GP})^{1}$ receptors. The initial interaction of one lectin binding site with one receptor oligosaccharide and then binding at multiple sites leads to rapid and stable cell cohesion (1). Recent studies suggest that human platelets may recapitulate some of these primitive cellular responses during the process of thrombin-induced aggregation. Platelets activated by thrombin develop membrane bound lectin activity that appears to be important in platelet aggregation (2). Gartner et al. (3) have shown that fibrinogen is the receptor for the endogenous lectin secreted by activated platelets. Thrombospondin (TSP) (4), also termed thrombin-sensitive protein (5) and glycoprotein G (6), is a major GP located in the $\alpha$-granules of human platelets $(7,8)$. It is secreted upon thrombin activation and binds to the platelet membrane in the presence of calcium (9). Recent studies suggest that TSP is the endogenous lectin of human platelets (10). In this paper, we present direct evidence demonstrating complex formation of fibrinogen with TSP.

\section{METHODS}

Materials. Lentil lectin (lens culinaris hemagglutinin), glucosamine, mannosamine, $\boldsymbol{N}$-acetyl glucosamine, $\boldsymbol{N}$-acetyl mannosamine, arginine, glycine, $p$-nitrophenyl phosphate, and type VII calf mucosa alkaline phosphatase were obtained from Sigma Chemical Co., St. Louis, MO. Protein A was obtained from Pharmacia Fine Chemicals, Div. of Pharmacia Inc., Piscataway, NJ. Microtitration plates and a Titertek multiscan photometer were purchased from Flow Laboratories, Inc., Rockville, MD. All reagents were of analytical grade.

Protein purification. Chromatographically pure peak 1 human fibrinogen prepared by the method of Finlayson and Mosesson (11) (kindly supplied by Dr. M. Mosesson, Downstate Medical Center) was free of Factor XIII, plasminogen,

\footnotetext{
${ }^{1}$ Abbreviations used in this paper: ELISA, enzyme linked immunosorbent assay; GP, glycoprotein; SDS-PAGE, sodium dodecyl sulfate-polyacrylamide gel electrophoresis; TSP, thrombospondin.
} 
Factor VIII antigen (VIII:AGN), and fibronectin as determined by lack of reactivity using monospecific antisera to these potential contaminants in an enzyme-linked immunosorbent assay (ELISA). The clottability of this fibrinogen was $\sim 96 \%$. The protein migrated as a single band on $5 \%$ sodium dodecyl sulfate-polyacrylamide gel electrophoresis (SDS-PAGE) with an estimated $M_{\mathrm{r}}$ of 330,000 . The reduced protein in SDS-PAGE revealed a typical distribution of $A \alpha-$ $\mathrm{B} \beta$-, and $\gamma$-chains with absence of degradation products. When chromatographed on a Sepharose CL-6B column (1.5 $\times 45 \mathrm{~cm}$ ) in $0.25 \mathrm{M} \mathrm{NaCl}, 0.05 \mathrm{M}$ Tris- $\mathrm{HCl}, \mathrm{pH} 8.6$, fibrinogen eluted as a single sharp peak indicating freedom from detectable quantities of fibrin monomers (12). TSP was isolated from thrombin-treated platelet supernate by Sepharose 4B gel exclusion chromatography followed by heparin-Sepharose affinity chromatography as described by Lawler et al. (4). The TSP was $>95 \%$ pure when analyzed by SDS-PAGE with an apparent $M_{\mathrm{r}}$ of 185,000 following reduction (9) (Fig. 1). It was free of plasminogen, fibronectin, and Factor VIII:AGN by ELISA. Platelet membrane GPIIb and GPIIIa were isolated and purified using lentil lectin affinity chromatography and electrophoretic elution from SDS-PAGE gels (13). $\alpha_{2}$-Plasmin inhibitor purified by the method of Wiman (14), plasminogen isolated from plasma by lysine affinity chromatography (15) and gel filtration chromatography, and antithrombin III were kindly provided by Dr. Peter Harpel, Cornell University Medical College. Factor VIII:AGN and fibronectin were isolated from human plasma $(16,17)$. Purified human albumin and $\gamma$-globulin were obtained from Behring Diagnostics, Inc., Woodbury, NY.

Antisera. Antisera to chromatographically pure peak 1 human fibrinogen, $\alpha_{2}$-plasmin inhibitor, and antithrombin III were kindly supplied by Dr. Peter Harpel. The antifibrinogen serum following two times absorption with insol-

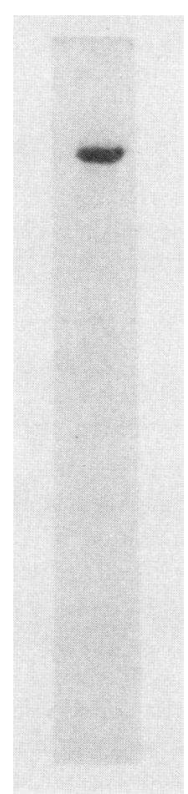

Figure 1 SDS-PAGE of purified TSP. Laemmli system, $3.9 \%$ stacking gel, and $7.5 \%$ separation gel. Approximately $50 \mu \mathrm{g}$ of protein was applied. The protein was reduced with $2 \%$ dithiothreitol. ubilized pooled human serum (18) failed to react by ELISA with purified human albumin, fibronectin, plasminogen, Factor VIII:AGN, or partially purified TSP mixture. Antisera to purified TSP were raised in rabbits (16). The anti-TSP serum was absorbed two times with insolubilized human fibrinogen and failed to react by ELISA with purified human albumin, fibrinogen, fibronectin, plasminogen, and Factor VIII:AGN. Monospecific anti-Factor VIII:AGN and antiplatelet GPIIb and GPIIIa and antifibronectin were prepared as described $(13,16,17)$. Antialbumin was obtained from Behring Diagnostics. $\gamma$-Globulin fractions of the various antisera were prepared as described (16).

ELISA. The performance of the assay was essentially as described by Voller et al. (19). Microtitration plates were coated with purified TSP. $0.2-\mathrm{ml}$ portions of the TSP in the bicarbonate-coating buffer (15 $\mathrm{mM} \mathrm{Na} \mathrm{Na}_{3}, 34.8 \mathrm{mM}$ $\mathrm{NaHCO}_{3}, \mathrm{pH} 9.6,0.02 \% \mathrm{NaN}_{3}$ ) were incubated in a humid chamber overnight at $4^{\circ} \mathrm{C}$. Optimum binding occurred at TSP concentrations of $2-4 \mu \mathrm{g} / \mathrm{ml}$. Contents of the microtitration plates were removed and the wells washed three times with Tris-Tween buffer $(0.01 \mathrm{M}$ Tris, $0.15 \mathrm{M} \mathrm{NaCl} \mathrm{pH}$ 7.4 , containing $0.05 \%$ Tween 20 ). The solution containing the purified fibrinogen was diluted in Tris-Tween buffer and added in duplicate to coated wells and the plates incubated overnight at $4^{\circ} \mathrm{C}$. The washing procedure was repeated and monospecific fibrinogen antiserum, diluted to final concentration of $1: 1,500$ in Tris-Tween buffer, was added for 24 $\mathrm{h}$ at $4^{\circ} \mathrm{C}$. The washing procedure was repeated and alkaline phosphatase-labeled protein A $(0.125 \mu \mathrm{g} / \mathrm{ml})$ prepared by the method of Engvall (20) as previously described (21) was added for 3 -h incubation at $4^{\circ} \mathrm{C}$. The wells were emptied, the wash step repeated, and $0.2 \mathrm{ml}$ of the substrate $p$-nitrophenyl phosphate $(1 \mathrm{mg} / \mathrm{ml}$ in $10 \%$ diethanolamine buffer, pH 9.8) added. The color development was followed at 15min intervals by repeated readings at $405 \mathrm{~nm}$ in a Titertek multiscan photometer. Color development with time was plotted and the best-fit curve was calculated by linear regression analysis. The formation of the fibrinogen-TSP complex was expressed as the enzymatic activity of the bound alkaline phosphatase $\left(\Delta \mathrm{A} 405 \mathrm{~min}^{-1}\right)$.

Determination of protein-coating efficiency on microtitration plate. Purified human TSP, fibrinogen, fibronectin, plasminogen and Factor VIII:AGN were labeled with ${ }^{125} \mathrm{I}$ using the modified chloramine-T method (12). Microtitration plates were coated in duplicate with $0.2-\mathrm{ml}$ portions of the labeled proteins at increasing concentrations in the bicarbonate-coating buffer at $4^{\circ} \mathrm{C}$ overnight as described above. After washing three times with Tris-Tween buffer, each well was cut out, radioactivity of the coated protein counted, and the coating efficiency for each protein determined. The saturating amounts of proteins that could be coated per well were $0.92 \mathrm{pmol}$ (TSP), $0.7 \mathrm{pmol}$ (fibrinogen), $3.4 \mathrm{pmol}$ (plasminogen), $1.2 \mathrm{pmol}$ (fibronectin), and $0.3 \mathrm{pmol}$ (VIII:AGN). Optimal coating concentration was $4 \mu \mathrm{g} / \mathrm{ml}$ for the various proteins. Thus, the coating efficiency for the proteins tested, i.e., TSP, fibrinogen, plasminogen, fibronectin, and Factor VIII:AGN were comparable.

\section{RESULTS}

ELISA of purified human fibrinogen. Monospecific antifibrinogen reacted with the purified human fibrinogen in an ELISA assay. Fibrinogen in increasing concentrations was passively adsorbed to the wells of the microtitration plate. Antifibrinogen serum at 


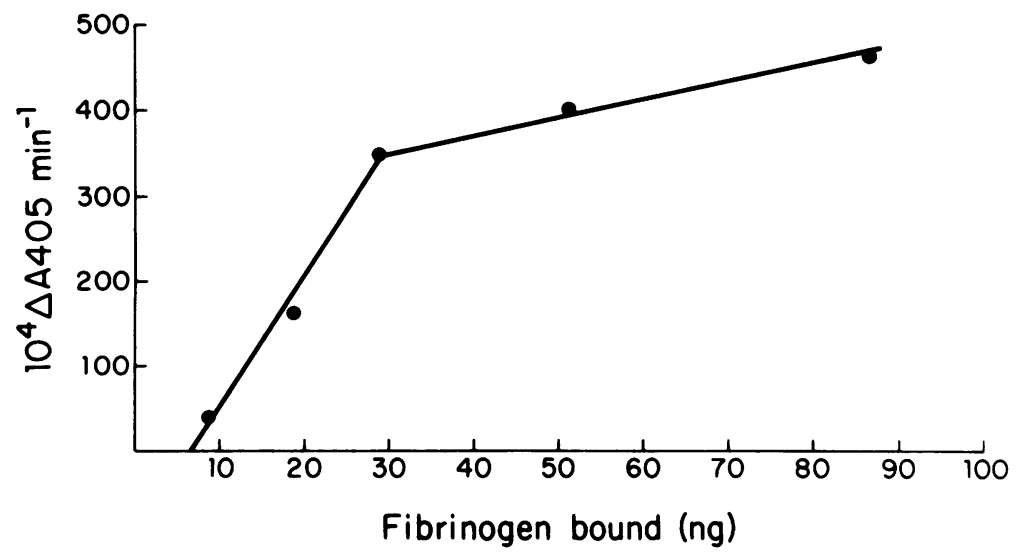

FIGURE 2 Correlation of the amount of fibrinogen bound and the color generated in the ELISA. The radiolabeled purified human fibrinogen varying from 0.1 to $16 \mu \mathrm{g} / \mathrm{ml}$ in coating buffer was applied to the plastic wells for $18 \mathrm{~h}$ at $4^{\circ} \mathrm{C}$. After washing, antifibrinogen serum $(1: 1,500$ dilution) was added for $24 \mathrm{~h}$ at $4^{\circ} \mathrm{C}$. After washing, alkaline phosphatase-labeled protein $\mathrm{A}$ $(0.125 \mu \mathrm{g} / \mathrm{ml})$ was added for $3 \mathrm{~h}$ at room temperature. After washing, the substrate $p$-nitrophenyl phosphate was added and color development followed in a Titertek multiscan photometer. The reaction was expressed as the enzymatic activity of the bound alkaline phosphatase $\left(10^{4} \times \Delta \mathrm{A} 405 \mathrm{~min}^{-1}\right)$. The wells were then washed, cut out and counted, and the amount of protein in each well determined. $y, 15.32 \mathrm{x}-106.34 ; r, 0.99$ (for the first three points of the curve).

1:1,500 dilution was added. The amount of antibody bound to the adsorbed fibrinogen was monitored by incubation with alkaline phosphatase-labeled protein A. The resulting hydrolysis of the substrate $p$-nitrophenyl phosphate was linear with the concentration of fibrinogen added to the well up to $300 \mathrm{ng} / \mathrm{ml}$.

Using ${ }^{125}$ I-labeled fibrinogen, the actual amount of fibrinogen bound to the plastic well was determined at each concentration of protein added and this was correlated with the color generated in the ELISA (Fig. 2). It should be noted that no differences in reactivity with specific antibody were noted when nonlabeled fibrinogen was compared with ${ }^{125}$ I-labeled fibrinogen.

Complex formation of fibrinogen with TSP. Fibrinogen attached and formed a complex with the TSP adsorbed to the wells of the plastic microtitration plate. The extent of the complex formation was determined by the enzymatic activity of the bound alkaline phosphatase coupled to protein A (Table I). No significant enhancement of the complex formation was noted in the presence of $0.5 \mathrm{mM} \mathrm{Ca}^{++}$.

To ascertain the possibility that the observed fibrinogen binding property of TSP might be due to a trace of contaminating protein undetected in SDS-PAGE by Coomassie Blue (Fig. 1), binding studies were performed by adding fluid-phase ${ }^{125}$ I-labeled TSP to fibrinogen-coated wells. The bound radiolabeled proteins were solubilized with $2 \%$ SDS, reduced with $2 \%$ dithiothreitol, and analyzed by SDS-PAGE. The solubilized, bound protein contained a single radioactive peak of $185,000 M_{r}$, which coincided with the major radioactive peak in the reduced pure TSP sample.

Specificity of the fibrinogen-TSP complex formation. Complex formation of fibrinogen with adsorbed TSP was determined in the presence of excess fluidphase TSP. Following the coating of TSP $(4 \mu \mathrm{g} / \mathrm{ml})$ on the microtitration plate, fibrinogen $(4 \mu \mathrm{g} / \mathrm{ml})$ was incubated with Tris-Tween buffer in the presence of $4 \mu \mathrm{g} / \mathrm{ml}$ fluid-phase TSP. The amount of fibrinogen

TABLE I

ELISA Detection of Fibrinogen-TSP Complex Formation

\begin{tabular}{cc}
\hline Antiserum & $10^{4} \times \Delta \mathrm{A405} \mathrm{min}^{-1}$ \\
\hline Antifibrinogen & $129 \pm 6.4$ \\
Antialbumin & $2 \pm 0.8$ \\
\hline
\end{tabular}

TSP $(4 \mu \mathrm{g} / \mathrm{ml})$ in bicarbonate-coating buffer was applied to the plastic wells for $18 \mathrm{~h}$ at $4^{\circ} \mathrm{C}$. After washing, fibrinogen $(4 \mu \mathrm{g} / \mathrm{ml})$ in Tris-Tween buffer was added for $24 \mathrm{~h}$ at $4^{\circ} \mathrm{C}$. The control contained only Tris-Tween buffer. After washing, monospecific antifibrinogen at 1:1,500 dilution was added for $24 \mathrm{~h}$ at $4^{\circ} \mathrm{C}$. After washing, alkaline phosphatase-labeled protein A $(0.125 \mu \mathrm{g} / \mathrm{ml})$ was added for $3 \mathrm{~h}$ at room temperature. After washing, the substrate $p$-nitrophenyl phosphate was added and enzymatic activity of the bound alkaline phosphatase was determined $\left(10^{4} \times \Delta \mathrm{A} 405 \mathrm{~min}^{-1}\right)$. Complex formation was expressed as the enzyme activity obtained in the presence of fluid-phase fibrinogen minus the buffer control. Additional control studies were performed with antialbumin substituting for antifibrinogen. 
detectable as a complex with the adsorbed TSP was markedly decreased (85\% inhibition). The small amount of fibrinogen that complexed to adsorbed TSP in the presence of excess soluble TSP was considered nonspecific binding. No inhibition of fibrinogen complex formation with TSP was detected when the experiments were repeated in the presence of comparable amounts of fluid-phase purified human albumin (Table II). Similarly, no inhibition of fibrinogen complex formation with TSP was detected in the presence of fluidphase $\gamma$-globulin, Factor VIII:AGN, or fibronectin (data not shown).

The specificity of the fibrinogen interaction with adsorbed TSP was studied further by incubating fluidphase fibrinogen in separate experiments with adsorbed Factor VIII:AGN, fibronectin, or plasminogen (Table III). Minimal complex formation was detected with purified fibronectin and purified plasminogen. These latter two protein preparations did not contain TSP using anti-TSP in an ELISA assay.

The specificity of the interaction of adsorbed TSP with fibrinogen was also studied by incubating various fluid-phase proteins in separate experiments with adsorbed TSP (Table IV). Fibronectin, which was fibrinogen free by ELISA, showed small but reproducible complex formation.

Stoichiometry of the fibrinogen-TSP complex formation. Saturation of the binding or complexing of fibrinogen to adsorbed TSP was determined by plotting the specific binding (total minus nonspecific) of incremental amount of fibrinogen to a fixed amount of adsorbed TSP (Fig. 3). The amount of fibrinogen bound at each concentration was determined from the color generated in the ELISA using the fibrinogen standard curve (Fig. 2). A Scatchard plot analysis of these data revealed an apparent dissociation constant $\left(K_{d}\right)$ for fibrinogen of $3.4 \mathrm{nM}$ and the maximum amount of fibrinogen bound per well was determined to be $12.7 \mathrm{ng}$ (Fig. 3, inset). Using radiolabeled TSP, the coating efficiency of TSP at $2 \mu \mathrm{g} / \mathrm{ml}$ was $34.4 \%$, corresponding to $137.7 \mathrm{ng}$ of TSP bound per well. Assum-

TABLE II

Inhibition of Complex Formation by Fluid-Phase TSP

\begin{tabular}{lc}
\hline \multicolumn{1}{c}{ Mixture } & $10^{4} \times \Delta \mathrm{A} 405 \mathrm{~min}^{-1}$ \\
\hline Fibrinogen & $113 \pm 3.0$ \\
Fibrinogen plus fluid-phase TSP & $19 \pm 1.7$ \\
Fibrinogen plus fluid-phase albumin & $117 \pm 2.2$ \\
\hline
\end{tabular}

TSP $(4 \mu \mathrm{g} / \mathrm{ml})$ in coating buffer was applied to the plastic wells for $18 \mathrm{~h}$ at $4^{\circ} \mathrm{C}$. After washing, fibrinogen $(4 \mu \mathrm{g} / \mathrm{ml})$ was added alone or in the presence of TSP $(4 \mu \mathrm{g} / \mathrm{ml})$ or albumin $(4 \mu \mathrm{g} / \mathrm{ml})$. The remaining steps were carried out as described in Table $I$.
TABLE III

Interaction of Fluid-Phase Fibrinogen with Adsorbed Proteins

\begin{tabular}{lc}
\hline Protein coat & $10^{4} \times \Delta \mathrm{A405} \mathrm{min}^{-1}$ \\
\hline None & $2.2 \pm 0.7$ \\
VIII:AGN & $5.5 \pm 1.3$ \\
Fibronectin & $11.5 \pm 2.1$ \\
Plasminogen & $11.9 \pm 1.7$ \\
TSP & $129 \pm 6.4$ \\
\hline
\end{tabular}

The proteins $(4 \mu \mathrm{g} / \mathrm{ml})$ in coating buffer were applied separately to plastic wells for $18 \mathrm{~h}$ at $4^{\circ} \mathrm{C}$. After washing, fibrinogen $(4 \mu \mathrm{g} /$ $\mathrm{ml}$ ) in Tris-Tween buffer was added for $24 \mathrm{~h}$ at $4^{\circ} \mathrm{C}$. The remaining steps were carried out as described in Table I.

ing a $M_{\mathrm{r}}$ of 420,000 for TSP (22), and $M_{\mathrm{r}}$ of 330,000 for fibrinogen, the data suggest a stoichiometric relationship of TSP to fibrinogen of 9:1.

Effect of amino sugars and amino acids on the $f$ brinogen-TSP complex formation. Previous studies have suggested that specific amino sugars such as glucosamine and mannosamine and amino acids, such as arginine, block platelet lectin activity $(2,10)$, and interfere with platelet fibrinogen binding (23). Glucosamine, mannosamine, and arginine partially inhibited fibrinogen complex formation with TSP (Table V). In contrast, $\mathrm{N}$-acetyl glucosamine, $\mathrm{N}$-acetyl mannosamine, and glycine had no effect. This same spectrum of inhibitory activity was observed on fibronectin-TSP complex formation (data not shown).

Influence on fibrinogen-TSP complex formation by platelet GPIIb and GPIIIa. Previous studies have demonstrated that isolated platelet membrane GPIIb and GPIIIa form a calcium-dependent complex with fibrinogen (21). The GPIIb-GPIIIa macromolecular

TABLE IV

Interaction of Adsorbed TSP with Other Fluid-Phase Proteins

\begin{tabular}{lc}
\hline \multicolumn{1}{c}{ Proteins } & $10^{4} \times \Delta \mathrm{A405} \mathrm{min}^{-1}$ \\
\hline Albumin & $2.0 \pm 0.65$ \\
$\gamma$-Globulin & $4.0 \pm 0.84$ \\
VIII:AGN & $5.0 \pm 1.4$ \\
$\alpha_{2}$-Plasmin inhibitor & $3.1 \pm 0.9$ \\
Fibronectin & $22 \pm 2.5$ \\
Platelet GPIIb-GPIIIa & $4.0 \pm 1.1$ \\
Antithrombin III & $1.4 \pm 0.6$ \\
\hline
\end{tabular}

TSP $(4 \mu \mathrm{g} / \mathrm{ml})$ in coating buffer was applied to the plastic wells for $18 \mathrm{~h}$ at $4^{\circ} \mathrm{C}$. After washing, the indicated fluid-phase proteins $(4 \mu \mathrm{g} / \mathrm{ml})$ were added for $24 \mathrm{~h}$ at $4^{\circ} \mathrm{C}$. The remaining steps were carried out as described in Table I except that the corresponding monospecific antisera used were applied at dilutions varying from 1:100 to 1:1,500, as determined by previous ELISA titrations. 


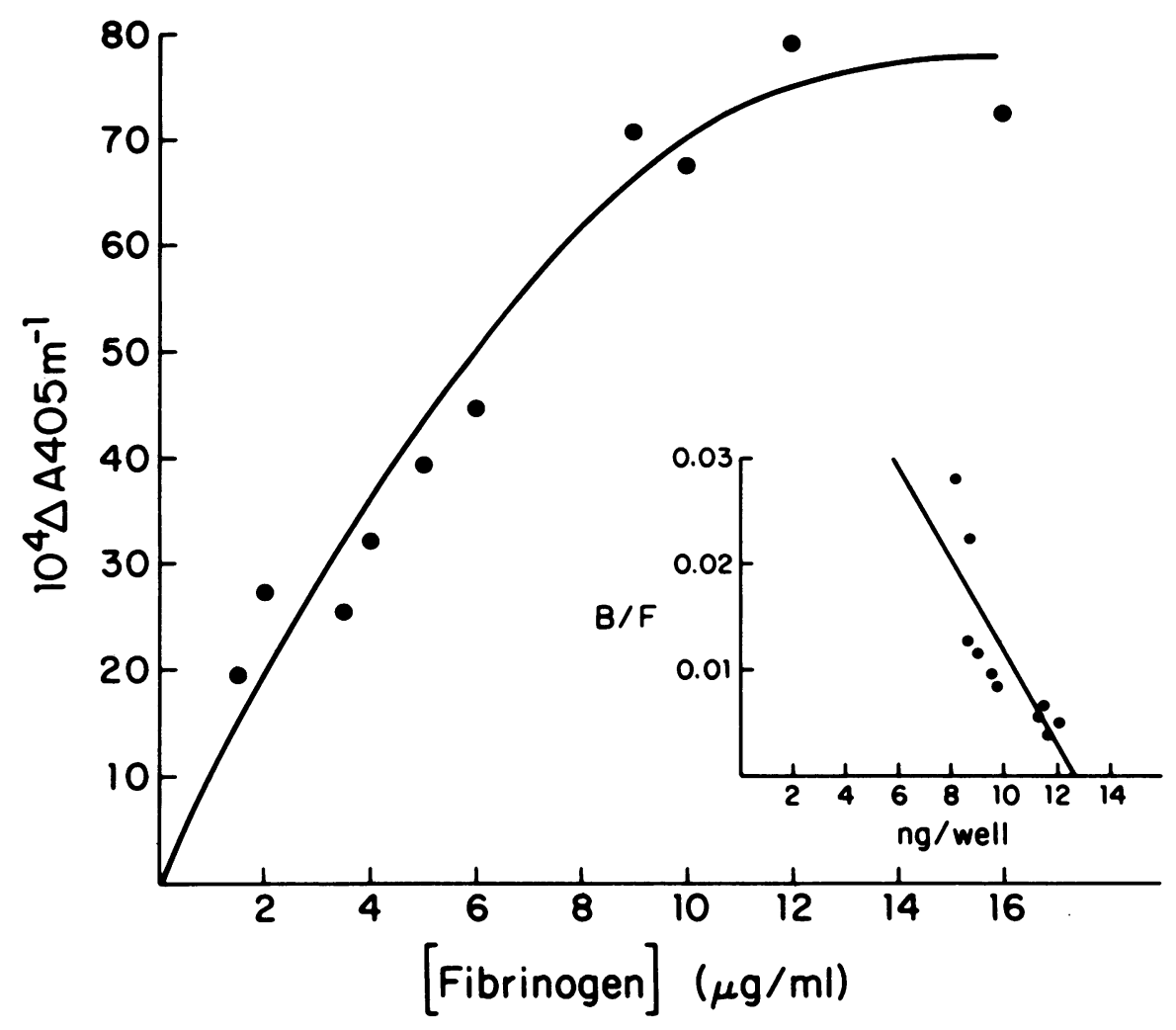

FIGURE 3 Saturation of fibrinogen complex formation with adsorbed TSP as measured by the ELISA. TSP $(2 \mu \mathrm{g} / \mathrm{ml})$ in coating buffer was applied to the plastic wells for $18 \mathrm{~h}$ at $4^{\circ} \mathrm{C}$. After washing, varying amounts of fibrinogen in Tris-Tween buffer were added alone or in the presence of TSP $(32 \mu \mathrm{g} / \mathrm{ml})$ for $24 \mathrm{~h}$ at $4^{\circ} \mathrm{C}$. The remaining steps were carried out as described in Table I. The extent of specific fibrinogen complex formation with adsorbed TSP (total minus nonspecific) was plotted as a function of increasing fibrinogen concentration. Inset: Scatchard plot of fibrinogen binding to adsorbed TSP from Fig. $3 . y,-0.0044 x+0.055 ; r,-0.815$.

complex on the platelet surface may act as a fibrinogen binding site (24). Binding studies were performed using the ELISA system to determine whether GPIIb and GPIIIa in the fluid phase competed with adsorbed TSP for fibrinogen complex formation. No inhibition of fibrinogen complex formation with TSP was noted in the presence of the platelet membrane GP (Table VI). Alternatively, fibrinogen was adsorbed to the microtitration wells and a mixture of GPIIb-GPIIIa and TSP was added. Binding of TSP and GPIIb-GPIIIa to fibrinogen was probed by the appropriate monospecific antisera. TSP did not inhibit the binding of GPIIbGPIIIa to fibrinogen. Conversely, GPIIb-GPIIIa did not interfere with the binding of TSP to fibrinogen (Table VI).

\section{DISCUSSION}

Platelets activated by thrombin develop membranebound lectin activity that appears to be important in platelet aggregation (2). Gartner et al. (3) have shown that fibrinogen is the receptor for the endogenous lectin secreted by activated platelets. Recent studies suggest that TSP is the endogenous lectin of human platelets (10). Thus, TSP agglutinates formalinized trypsintreated sheep erythrocytes, an activity blocked by glucosamine and mannosamine, but not by $\mathrm{N}$-acetyl glucosamine or $N$-acetyl mannosamine. In addition, TSP blocked hemagglutination induced by formalinized thrombin-treated platelets (10).

In this study, we have demonstrated that purified human fibrinogen forms a complex with purified TSP. The formation of the fibrinogen-TSP complex is specific, saturable, and inhibited by specific amino sugars and amino acids. These same inhibitors have been shown previously to block platelet lectin activity (2) and TSP lectin activity (10). It is of interest that the same amino sugars and amino acids also block thrombin-induced platelet aggregation (2). Platelets from 
TABLE V

Effects of Amino Sugars and Amino Acids on Fibrinogen-TSP Complex Formation

\begin{tabular}{lc}
\hline \multicolumn{1}{c}{ Fluid-phase fibrinogen } & $\begin{array}{c}\text { Complex } \\
\text { formation }\end{array}$ \\
\hline Buffer & $\%$ \\
Glucosamine & 100 \\
$N$-Acetyl-glucosamine & 36.5 \\
Mannosamine & 110.4 \\
N-Acetyl-mannosamine & 67.3 \\
Arginine & 149 \\
Glycine & 34 \\
Glucose & 155 \\
\hline
\end{tabular}

TSP $(4 \mu \mathrm{g} / \mathrm{ml})$ in coating buffer was applied to the plastic wells for $18 \mathrm{~h}, 4^{\circ} \mathrm{C}$. After washing, fibrinogen $(4 \mu \mathrm{g} / \mathrm{ml})$ in Tris-Tween buffer containing the above was added for $24 \mathrm{~h}$ at $4^{\circ} \mathrm{C}$. The amino sugars and amino acids were used at final concentrations of 100 $\mathrm{mM}$ except for mannosamine and $\mathrm{N}$-acetyl mannosamine that were used at $30 \mathrm{mM}$. The $\mathrm{pH}$ of the incubation mixture in all cases was adjusted to 7.4 with $\mathrm{HCl}$. The remaining steps were carried out as described in Table I. Buffer control was considered 100\% complex formation.

patients with the gray platelet syndrome, a selective deficiency of $\alpha$-granules, do not aggregate normally upon stimulation with thrombin (8). These observations suggest that the formation of the fibrinogen-TSP complex on the platelet surface may play an important role in thrombin-induced platelet aggregation.

It is of interest that the adsorbed TSP also formed a complex with fibrinogen-free fibronectin. The extent of fibronectin-TSP complex formation was signifi- cantly less than the fibrinogen-TSP complex formation. Recent studies have shown that fibronectin binds to thrombin-stimulated platelets (25). It is possible that TSP secreted from the $\alpha$-granules and bound to the platelet membrane serves as the site of fibronectin attachment; however, the role of fibronectin in platelet membrane function remains to be determined.

The stoichiometry of the fibrinogen-TSP interaction on the plastic microtitration plates suggests that one fibrinogen molecule was bound per nine adsorbed TSP molecules, with a $K_{\mathrm{D}}$ of $3.4 \mathrm{nM}$. The stoichiometric relationship of the interacting constituents must be interpreted with some caution. Thus, these studies utilize a plastic surface with coated TSP molecules. It is highly probable that the adsorbed TSP molecules are oriented in a random manner with significant steric restriction. Thus, only a fraction of the adsorbed TSP may be functionally capable of binding to the soluble fibrinogen. These considerations make it likely that the 9:1 stoichiometry is an overestimation. More physiologically relevant surfaces, such as liposomes, may be more appropriate for defining the stoichiometry and affinity of this complex formation.

What is the relationship of fibrinogen complex formation with membrane-bound TSP to normal aggregation, which appears to be dependent on fibrinogen binding? Previous data strongly suggest that platelet GPIIb and GPIIIa are major components of the platelet plasma membrane that are important in aggregation. These GP are missing or markedly diminished in Glanzmann's thrombasthenia, a hereditary bleeding disorder characterized by defective platelet aggregation (25). ADP, epinephrine, and thrombin-induced fibrinogen binding in normal platelets correlates with

TABLE VI

Influence on Fibrinogen-TSP Complex Formation by GPIIb and GPIIIa

\begin{tabular}{|c|c|c|c|}
\hline Protein coat & Fluid phase & Antibody probe & $10^{4} \times \Delta \mathrm{A405} \mathrm{min}^{-1}$ \\
\hline \multirow[t]{2}{*}{ TSP } & Fibrinogen & Antifibrinogen & $102 \pm 3.5$ \\
\hline & Fibrinogen + GPIIb-GPIIIa & Antifibrinogen & $106 \pm 1.8$ \\
\hline \multirow[t]{4}{*}{ Fibrinogen } & TSP & Anti-TSP & $58.3 \pm 6.0$ \\
\hline & TSP + GPIIb-GPIIIa & Anti-TSP & $51.2 \pm 11$ \\
\hline & GPIIb-GPIIIa & Anti-GPIIb + anti-GPIIIa & $64.1 \pm 0.3$ \\
\hline & TSP + GPIIb-GPIIIa & Anti-GPIIb + anti-GPIIIa & $70.5 \pm 9.2$ \\
\hline
\end{tabular}

For experiments with TSP-coated wells, TSP $(4 \mu \mathrm{g} / \mathrm{ml})$ in coating buffer was applied to the plastic wells for $18 \mathrm{~h}$ at $4^{\circ} \mathrm{C}$. After washing, fibrinogen $(4 \mu \mathrm{g} / \mathrm{ml})$ in $0.5 \mathrm{mM} \mathrm{Ca}^{++}$Tris-Tween buffer was added for $24 \mathrm{~h}$ at $4^{\circ} \mathrm{C}$, in the presence or absence of a mixture of GPIIb-GPIIIa $(4 \mu \mathrm{g} / \mathrm{ml})$. For experiments with fibrinogen-coated wells, fibrinogen $(4 \mu \mathrm{g} / \mathrm{ml})$ was coated in a similar manner, followed by the addition of TSP $(4 \mu \mathrm{g} / \mathrm{ml})$ and/or GPIIb-GPIIIa $(4 \mu \mathrm{g} / \mathrm{ml})$ in $1 \mathrm{mM} \mathrm{Ca}{ }^{++}$Tris-Tween buffer. The remaining steps were carried out as described in Table I. Anti-GPIIb and anti-GPIIIa were used in 1:100 dilution and anti-TSP in 1:1,000 dilution. 
aggregation, while nonaggregating thrombasthenic platelets do not bind fibrinogen $(12,27,28)$. We have previously demonstrated that clustering of GPIIb and GPIIIa complexes occur in the thrombin-stimulated platelet membrane (29), and that GPIIb-GPIIIa complexes bind fibrinogen (21). In this study, GPIIb and GPIIIa mixtures did not inhibit complex formation of fibrinogen with TSP (Table VI). This suggests that the binding sites of fibrinogen for TSP are different from the binding sites for the membrane GP. It is of interest that recent data suggest that there may be two different classes of fibrinogen receptors in normal human platelets $(30,31)$. Our data raise the possibility that asymmetrical protein bridges form between aggregating platelets following thrombin stimulation. TSP released from $\alpha$-granules fixed to the membrane of one cell may bind fibrinogen, which is bound to a GPIIbGPIIIa cluster on an adjacent cell. It remains to be determined whether symmetrical bridges may form under some circumstances with fibrinogen linking two TSP sites on different cells. The precise molecular interactions on the platelet membrane leading to aggregation remain to be fully clarified. The studies reported here support the hypothesis that the interaction of fibrinogen with TSP on the activated platelet surface may be an important step in the platelet aggregation process.

\section{ACKNOWLEDGMENTS}

We thank Dr. M. Mosesson for the supply of purified peak 1 human fibrinogen and Dr. P. Harpel for the supply of $\alpha_{2}$-plasmin inhibitor, antithrombin III, plasminogen, and antisera to peak 1 human fibrinogen. The invaluable technical assistance of Barbara Ferris is gratefully acknowledged.

This work was supported by grant HL 18828 (Specialized Center of Research in Thrombosis) from the National Institutes of Health. Additional support was provided by the Arnold Krakower Foundation.

\section{REFERENCES}

1. Frazier, W., and L. Glaser. 1979. Surface components and cell recognition. Annu. Rev. Biochem. 48: 491-523.

2. Gartner, K. T., D. C. Williams, F. C. Minion, and D. R. Phillips. 1978. Thrombin-induced platelet aggregation is mediated by a platelet plasma membrane-bound lectin. Science (Wash. DC). 200: 1281-1283.

3. Gartner, K. T., J. M. Gerrard, J. G. White, and D. C. Williams. 1981. Fibrinogen is the receptor for the endogenous lectin of human platelets. Nature (Lond.). 289: 688-690.

4. Lawler, J. W., H. S. Slayter, and J. E. Coligan. 1978. Isolation and characterization of a high molecular weight glycoprotein from human blood platelets. J. Biol. Chem. 273: 8609-8616.

5. Baenziger, N. L., G. N. Brodie, and P. W. Majerus. 1971. A thrombin-sensitive protein of human platelet membranes. Proc. Natl. Acad. Sci. U.S.A. 68: 240-243.
6. George, J. N. 1978. Studies on platelet plasma membranes. IV. Quantitative analysis of platelet membrane glycoproteins by ${ }^{125}$ I-diazotized diiodosulfanilic acid labeling and SDS-polyacrylamide gel electrophoresis. J. Lab. Clin. Med. 92: 430-446.

7. Hagen, I. 1975. Effects of thrombin on washed human platelets: changes in subcellular fraction. Biochim. Biophys. Acta. 392: 242-254.

8. Gerrard, J. M., D. R. Phillips, G. H. Rao, E. F. Plow, D. A. Walz, R. Ross, L. A. Harker, and J. G. White. 1980. Biochemical studies of two patients with the gray platelet syndrome: selective deficiency of platelet alpha granules. J. Clin. Invest. 66: 102-109.

9. Phillips, D. R., L. K. Jennings, and H. R. Prasanna. 1980. $\mathrm{Ca}^{2+}$-mediated association of glycoprotein-G (thrombinsensitive protein, thrombospondin) with human platelets. J. Biol. Chem. 255: 11629-11632.

10. Jaffe, E. A., L. L. K. Leung, R. L. Nachman, R. I. Levin, and D. F. Mosher. 1982. Thrombospondin is the endogenous lectin of human platelets. Nature (Lond.). 295: 246-248.

11. Finlayson, J. S., and M. W. Mosesson. 1963. Heterogeneity of human fibrinogen. Biochemistry. 2: 42-46.

12. Marguerie, G. A., E. F. Plow, and T. S. Edgington. 1979. Human platelets possess an inducible and saturable receptor specific for fibrinogen. J. Biol. Chem. 254: 53575363.

13. Leung, L. L. K., T. Kinoshita, and R. L. Nachman. 1981. Isolation, purification, and partial characterization of platelet membrane glycoproteins IIb and IIIa. J. Biol. Chem. 256: 1994-1997.

14. Wiman, B. 1980. Affinity chromatographic purification of human $\alpha_{2}$-antiplasmin. Biochem. J. 191: 229-232.

15. Deutsch, D. G., and E. T. Mertz. 1970. Plasminogen: purification from human plasma by affinity chromatography. Science (Wash. DC). 170: 1095-1096.

16. Jaffe, E. A., and R. L. Nachman. 1975. Subunit structure of Factor VIII antigen synthesized by cultured human endothelial cells. J. Clin. Invest. 56: 698-702.

17. Resnick, G. D., and R. L. Nachman. 1981. Reed-Sternberg cells in Hodgkin's disease contain fibronectin. Blood. 57: 339-342.

18. Cuatrecasas, P. 1970. Protein purification by affinity chromatography. J. Biol. Chem. 245: 3059-3065.

19. Voller, A., D. Bidwell, and A. Bartlett. 1976. Microplate enzyme immunoassays for the immunodiagnosis of virus infections. In Manual of Clinical Immunology. N. R. Rose and $\mathbf{H}$. Friedman, editors. American Association of Microbiology, Wash. DC. 506-512.

20. Engvall, E. 1978. Preparation of enzyme-labeled staphylococcal protein $A$ and its use for detection of antibodies Scand. J. Immunol. 8(Suppl. 7): 25-31.

21. Nachman, R. L., and L. L. K. Leung. 1982. Complex formation of platelet membrane glycoproteins IIb and IIIa with fibrinogen. J. Clin. Invest. 69: 263-269.

22. Margossian, S. S., J. W. Lawler, and H. S. Slayter. 1981. Physical characterization of platelet thrombospondin. J. Biol. Chem. 256: 7495-7500.

23. Kinlough-Rathbone, R. L., A. Chahil, D. W. Perry, M. A. Packham, and J. F. Mustard. 1979. Effect of amino sugars that block platelet lectin activity on fibrinogen binding to washed rabbit or human platelets. Blood. 54(Suppl. 1): 249a.

24. McEver, R. P., N. L. Baenziger, and P. W. Majerus. 1980. Isolation and quantitation of the platelet mem- 
brane glycoprotein deficient in thrombasthenia using a monoclonal hybridoma antibody. J. Clin. Invest. 66: 1311-1318.

25. Plow, E. F., and M. H. Ginsberg. 1981. Specific and saturable binding of plasma fibronectin to thrombinstimulated platelets. J. Biol. Chem. 256: 9477-9482.

26. Nurden, A. T., and J. P. Caen. 1979. The different glycoprotein abnormalities in thrombasthenic and BernardSoulier platelets. Semin. Hematol. 16: 234-250.

27. Bennet, J. S., and G. Vilaire. 1979. Exposure of platelet fibrinogen receptors by ADP and epinephrine. J. Clin. Invest. 64: 1393-1401.

28. Plow, E. F., and G. A. Marguerie. 1980. Participation of ADP in the binding of fibrinogen to thrombin-stimulated platelets. Blood. 57: 553-555.

29. Polley, M. J., L. L. K. Leung, F. Y. Clark, and R. L. Nachman. 1981. Thrombin-induced platelet membrane glycoprotein IIb and IIIa complex formation: an electron microscope study. J. Exp. Med. 154: 1058-1068.

30. Peerschke, E. I., M. B. Zucker, R. A. Grant, J. J. Span, and M. J. Johnson. 1980. Correlation between fibrinogen binding to human platelets and platelet aggregability. Blood. 55: 841-847.

31. Niewiarowski, S., A. Z. Budzynski, T. A. Morinelli, T. M. Brudzynski, and G. J. Stewart. 1981. Exposure of fibrinogen receptor on human platelets by proteolytic enzymes. J. Biol. Chem. 254: 917-925. 